\title{
Multinuclear Magnetic Resonance Study of the Structure and Dynamics of Lanthanide(III) Complexes of the Bis(propylamide) of Diethylenetriaminepentaacetic Acid in Aqueous Solution
}

\author{
Carlos F. G. C. Geraldes, ${ }^{*}$, Ana M. Urbano, ${ }^{\dagger}$ Mattheus A. Hoefnagel, $\ddagger$ and Joop A. Peters ${ }^{*}$, \\ Department of Biochemistry, University of Coimbra, 3000 Coimbra, Portugal, and \\ Laboratory of Organic Chemistry and Catalysis, Delft University of Technology, \\ Julianalaan 136, 2628 BL Delft, The Netherlands
}

Received November 18, 1992

\begin{abstract}
The structure and dynamics of the lanthanide(III) complexes of the bis(propylamide) of diethylenetriaminepentaacetate (DTPA-PA $A_{2}$ ) in aqueous solution have been investigated by ${ }^{13} \mathrm{C}$ and ${ }^{17} \mathrm{O} \mathrm{NMR}$. With the use of the longitudinal ${ }^{13} \mathrm{C}$ relaxation times of the $\mathrm{Nd}^{\mathrm{III}}$ complex it is shown that the organic ligand is bound to the lanthanide(III) ion in an octadentate fashion via the three nitrogens of the diethylenetriamine backbone, the three carboxylate groups, and the two amide oxygens. ${ }^{17} \mathrm{O}$ NMR measurements show that the coordination sphere is completed by one water ligand. The inversion of the lanthanide-bound nitrogens is precluded, and therefore four diastereomeric pairs of isomers are possible for these complexes. Low-temperature ${ }^{13} \mathrm{C}$ NMR spectra show that all these isomers occur in solution. Three dynamic processes have been identified by means of variable-temperature NMR measurements: (i) rapid rotations of the carboxylate groups, (ii) racemization at the middle $\mathbf{N}$ atom via interconversions between the two possible conformations of the ethylene bridges, and (iii) racemization at the terminal $\mathrm{N}$ atoms of the diethylenetriamine backbone via decoordination-inversion-coordination. The barriers of the interconversions between the enantiomers have been determined by line-shape analysis and from coalescence temperatures. A comparison is made with the $\mathrm{Ln}^{\mathrm{III}}$ diethylenetriaminepentaacetate (DTPA) complexes.
\end{abstract}

\section{Introduction}

The rapid development of magnetic resonance imaging (MRI) has been of great importance to medical diagnosis. Although excellent soft-tissue images are obtained with this technique, early experiments showed that contrast agents might increase its diagnostic value immensely. Consequently, parallel with the development of MRI, there has been an explosive growth in interest for contrast agents. ${ }^{1-3}$ These agents can be applied to enhance the contrast of images, allowing for example an easier recognition of abnormal tissue. It is also possible to map regions in tissue with different accessibility to these reagents as a result of varying barrier permeabilities, flow, or perfusion and to visualize vascular disorders as infarction, stroke, or hypoxic/anoxic effects.

The Gd ${ }^{I I}$-diethylenetriamine- $N, N, N^{\prime}, N,{ }^{\prime \prime}, N^{\prime \prime}$-pentaacetate complex [Gd(DTPA) $\left.\left(\mathrm{H}_{2} \mathrm{O}\right)\right]^{2-}$ is the first contrast agent that has been approved for use in humans and is used nowadays on a routine basis. This paramagnetic complex contains one innersphere water molecule ${ }^{4-7}$ that exchanges rapidly ${ }^{8,9}$ with the bulk water in the body, thereby providing an efficient mechanism for the enhancement of the relaxation rates $\left(1 / T_{1}\right.$ and $\left.1 / T_{2}\right)$ of the water protons. The latter parameters contribute to the intensity of the MRI signal and thus the contrast of the images.

* Authors to whom correspondence should be addressed.

+ University of Coimbra.

t Delft University of Technology.

(1) Lauffer, R. B. Chem. Rev. 1987, 87, 901.

(2) Tweedle, M. F. In Lanthanide Probes in Life, Chemical and Earth Sciences; Bünzli, J.-C. G., Choppin, G. R., Eds.; Elsevier: Amsterdam, 1989; Chapter 5

(3) Tweedle, M. F. J. Alloys Comp. 1992, 180, 317

(4) Bryden, C. C.; Reilley, C. N. Anal. Chem. 1982, 54, 610.

(5) Peters, J. A. Inorg. Chem. 1988, 27, 4686.

(6) Geraldes, C. F. G. C.; Sherry, A. D.; Cacheris, W. P.; Kuan, K. T Brown, R. D., III; Koenig, S. H.; Spiller, M. Magn. Reson. Med. 1988, 8,191 .

(7) Chang, C. A.; Brittain, H. G.; Telser, J.; Tweedle, M. F. Inorg. Chem. $1990,29,4468$

(8) Micskei, K.; Helm, L.; Brücher, E.; Merbach, A. E. Abstracts of the 29th International Conference on Coordination Chemistry; Blackwell: Oxford, U.K., 1992; p 137.

(9) Clarkson, R. B.; Tsekos, N.; Knight, C.; Belford, R. L. Abstracts of the Society of Magnetic Resonance in Medicine Meeting, Berlin, Germany, 1992; p 1435.
A drawback of the Gd(DTPA) complex is that it has a negative charge, which, because it is usually administered at $0.5 \mathrm{M}$, results in a relatively high osmolality under physiological conditions and consequently undesired side effects. The adverse effects of ionic chelates are always higher than those of nonionic ones at the same concentration, ${ }^{10}$ and therefore the neutral $\mathrm{Gd}^{\mathrm{III}}$ complexes of bis(amide) analogues of DTPA (Chart I) and nonionic macrocyclic chelates derived from DOTA $(1,4,7,10$-tetraazacyclododecane- $N, N^{\prime}, N^{\prime \prime}, N^{\prime \prime \prime}$-tetraacetate) have recently been introduced as alternatives. ${ }^{6,11-15}$ The X-ray crystal structure of the GdIII complex of the bis(ethylamide) of DTPA (DTPA-EA ${ }_{2}$ ) revealed that in the solid state $\mathrm{Gd}^{\mathrm{III}}$ is coordinated to the three nitrogens, the three carboxylates, the two amide carbonyls, and one water. ${ }^{12}$ This structure is very similar to that of the $\mathrm{Ln}^{11 I}$ complexes of DTPA, both in the solid state and in aqueous solution. ${ }^{5,16-18}$

This paper reports the results of a multinuclear NMR study on the structure and the dynamics of the $\mathrm{Ln}^{\mathrm{III}}$ complexes of the bis(propylamide) of DTPA (DTPA-PA ${ }_{2}$ ) in aqueous solution. The $\mathrm{Ln}^{\mathrm{III}}$ complexes of a particular ligand are usually almost isostructural. Therefore one can profit from the different NMR properties of the various $\mathrm{Ln}^{\mathrm{II}}$ ions in structural analysis of these complexes. ${ }^{19,20}$ The $\mathrm{Nd}^{\mathrm{III}}$-induced ${ }^{13} \mathrm{C}$ relaxation rate enhancements were utilized to investigate the binding of the organic ligand,

(10) Baxter, A. B.; Melnikoff, S.; Stites, D. P.; Brasch, R. C. Invest. Radiol. 1991, 26, 1035 .

(11) Sherry, A. D.; Cacheris, W. P.; Kuan, K. T. Magn. Reson. Med. 1988, 8,180 .

(12) Konings, M. S.; Dow, W. C.; Love, D. B.; Raymond, K. N.; Quay, S. C.; Rocklage, S. M. Inorg. Chem. 1990, 29, 1488.

(13) Cacheris, W. P.; Quay, S. C.; Rocklage, S. M. Magn. Reson. Imaging $1990,8,467$.

(14) Van Wagoner, M.; O'Toole, M.; Worah, D.; Liese, P. T.; Quay, S. C. Invest. Radiol. 1991, 26, 980.

(15) Dischino, D. D.; Delaney, E. J.; Emswiler, J. E.; Gaughan, G. T.; Prasad, J. S.: Srivastava, S. K.; Tweedle, M. F. Inorg. Chem. 1991, 30, 1265

(16) Jenkins, B. G.; Lauffer, R. B. Inorg. Chem. 1988, 27, 4730

(17) Gries, H.; Miklautz, H. Physiol. Chem. Phys. Med. NMR 1984, 16, 105.

(18) Stekowski, J. J.; Hoard, J. L. Isr. J. Chem. 1984, 24, 323.

(19) Peters, J. A.; Kieboom, A. P. G. Recl. Trav. Chim. Pays-Bas 1983, 102. 381 . 
Chart I<smiles>[R]CN(CCN(CCN(C[R])CC(=O)[O-])CC(=O)[O-])CC(=O)[O-]</smiles>

$$
\begin{array}{lll}
\text { DTPA } & : & R=\mathrm{COO}^{-} \\
\text {DTPA-A口 } & : & R=C O N H_{2} \\
\text { DTPA-EA } & : & R=C O N H C H_{2} \mathrm{CH}_{3} \\
\text { DTPA-PA } & : & R=C O N \mathrm{CH}_{2} \mathrm{CH}_{2} \mathrm{CH}_{3}
\end{array}
$$

whereas the various $\mathrm{Ln}^{\mathrm{III}}$-induced ${ }^{17} \mathrm{O}$ water shifts were employed to determine the water coordination number. Variable-temperature studies were performed in order to get information on the dynamics of these complexes. A comparison is made with the previously studied L $n^{\text {III-DTPA system. }}{ }^{\text {S }}$ Some initial results of this study were published in a preliminary communication..$^{21}$

\section{Experimental Section}

Chemicals and Solutions. The ligand DTPA-PA ${ }_{2}$ was synthesized according to Sherry et al. " or by a procedure analogous to that reported for the corresponding bis(ethylamide) compound.12 DTPA-A ${ }_{2}$ was prepared analogous to the latter procedure, using a solution of $25 \%$ ammonia in water. This compound was obtained as an oil, and it was used without further purification. ${ }^{13} \mathrm{C}$ NMR $\left(100.6 \mathrm{MHz}, \mathrm{D}_{2} \mathrm{O}, \mathrm{pH}\right.$ 4.5): $\delta 52.41,53.81,56.61,59.04,59.42,173.50,175.91$, and 177.71 .

${ }^{17} \mathrm{O}$-enrichment of the carboxylate groups of DTPA-PA ${ }_{2}$ was achieved by heating the compound in 10\% ${ }^{17} \mathrm{O}$-enriched water (Icon Services, Inc., Summit, NJ) for $10 \mathrm{~h}$ at $90^{\circ} \mathrm{C}$, followed by evaporation of the solvent and drying the residue under vacuo over zeolite KA. It is known that under these conditions amide oxygens do not exchange with water. ${ }^{22}$

The La ${ }^{I I I}, \mathrm{Nd}^{\prime \prime \prime}$, and Dy"ll complexes were prepared according to a procedure analogous to that described by Raymond et al. for the Gd(DTPA-EA ${ }_{2}$ ) complex. ${ }^{12}$ The complexes were obtained as hydrates Ln(DTPA-PA 2$) \cdot n \mathrm{H}_{2} \mathrm{O}(n=1-3)$. The elemental analysis were within $0.3 \%$ of the theoretical values. The FAB mass spectra showed the expected $(\mathrm{M}+1)^{+}$cluster.

Samples of the $\mathrm{Ln}^{\prime \prime \prime}$ complexes for the NMR measurements were prepared by dissolution of solid $\operatorname{Ln}\left(D T P A \cdot P A_{2}\right)$ in $D_{2} O$ or by mixing of equimolar solutions of DTPA-PA ${ }_{2}$ and hydrated $\mathrm{LnCl}_{3}$ (Aldrich Chemical Co.), followed by adjustment of the $\mathrm{pH}$ with a solution of $\mathrm{NaOD}$ in $\mathrm{D}_{2} \mathrm{O}$. The $\mathrm{pH}$ of the solutions was measured at room temperature with a calibrated microcombination probe purchased from Aldrich Chemical Co. The $\mathrm{pH}$ values given are direct meter readings.

NMR Measurements. The NMR spectra were recorded with a Nicolet NT-200 WB or a Varian VXR-400 S spectrometer. For ${ }^{13} \mathrm{C}$ NMR tertbutyl alcohol was used as internal standard (methyl signal at $31.2 \mathrm{ppm}$ ). The ${ }^{17} \mathrm{O}$ chemical shifts were determined with respect to $\mathrm{D}_{2} \mathrm{O}$ as external standard. The chemical shifts of the ${ }^{17} \mathrm{O}$ signals were determined by fitting the observed signal with a Lorenzian line function. Downfieldinduced shifts are denoted as positive.

Longitudinal relaxation rates were measured with the Nicolet NT$200 \mathrm{WB}$ spectrometer by using a $\left[\left(90^{\circ}{ }_{x} 180^{\circ}{ }_{y} 90^{\circ}{ }_{x}\right)-\tau-90^{\circ}\right.$-acq $]$ inversion recovery pulse sequence. The $T_{1}$ values were calculated by using a threeparameter fit of the experimental data. ${ }^{23}$

\section{Results and Discussion}

${ }^{13} \mathrm{C}$ NMR Spectra. The ${ }^{13} \mathrm{C}$ NMR spectra of the diamagnetic $\mathrm{La}{ }^{11}$ - and $\mathrm{Lu}^{\mathrm{III}}$-DTPA-PA $\mathrm{A}_{2}$ complexes in $\mathrm{D}_{2} \mathrm{O}$ at $25^{\circ} \mathrm{C}$ indicated that various species were present in solution. Both complexes displayed two sets of signals for the propyl group. The Lall

(20) Sherry, A. D.; Geraldes, C. F. G. C. In Lanthanide Probes in Life, Chemical and Earth Sciences; Bünzli, J.-C. G., Choppin, G. R., Eds.; Elsevier: Amsterdam, 1989; Chapter 4.

(21) Geraldes, C. F. G. C.; Urbano, A. M.; Alpoim, M. C.; Hoefnagel, M. A.; Peters, J. A. J. Chem. Soc., Chem. Commun. 1991, 656.

(22) Mears, W. H.; Sobotka, H. J. Am. Chem. Soc. 1939, 61, 880.

(23) Levy, G. C.; Peat, I. R. J. Magn. Reson. 1975, 18, 500.

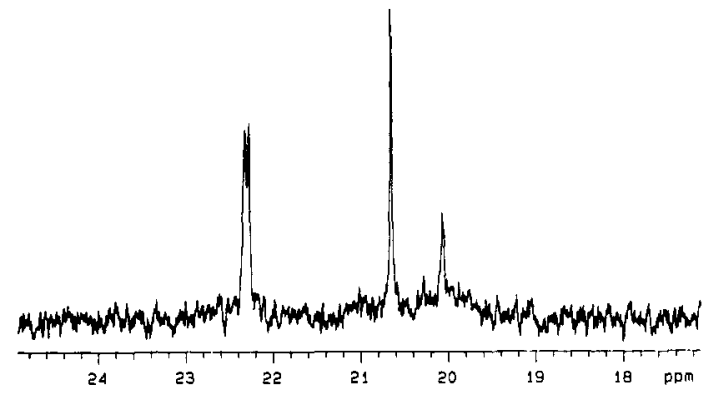

$70 \cdot \mathrm{C}$

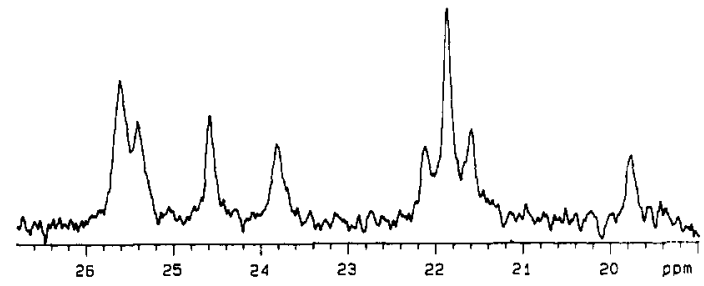

$-30^{\circ} \mathrm{C}$

Figure 1. Influence of the temperature on the $100.6-\mathrm{MHz}{ }^{13} \mathrm{C}$ NMR $\beta$-methylene carbons of the Nd(DTPA-PA 2 ) complex in $\mathrm{CD}_{3} \mathrm{OD}-\mathrm{D}_{2} \mathrm{O}$ $(1: 1, v / v)$.

complex showed five carboxylate and two a mide carbonyl signals, whereas in the ${ }^{13} \mathrm{C}$ NMR spectrum of the $\mathrm{Lu} \mathbf{u}^{\mathrm{III}}$ complex six carboxylate and four amide carbonyl signals could be discerned. ${ }^{24}$ The region between 56 and $68 \mathrm{ppm}$, in which the other signals occur, was very complex due to overlap of peaks. At room temperature ${ }^{13} \mathrm{C}$ NMR spectra of the paramagnetic complexes exhibited very broad and featureless signals, usually only signals for the propyl groups could be recognized. Increasing the temperature to $75^{\circ} \mathrm{C}$ resulted in an appreciable sharpening of the signals, and at this temperature good spectra for the complexes of the lighter lanthanides $\left(\mathrm{Ce} \rightarrow \mathrm{Eu}\right.$ ) with DTPA-PA $\mathrm{A}_{2}$ could be obtained (see supplementary material). The spectra for $L n=T b$ $\rightarrow$ Yb were still very broad, and therefore, these spectra were not taken into consideration. The broadening of the spectra can be ascribed to exchange phenomena as a result of the conformational mobility of the complexes. Similar phenomena have been observed with $\operatorname{Ln}$ (DTPA) complexes 5,16 and with $\mathrm{Ln}^{\text {III }}$ complexes of macrocyclic polyamino carboxylates, such as DOTA..$^{25}$

The spectra of the paramagnetic $\operatorname{Ln}\left(D_{T P A}-P_{2}\right)$ complexes at high temperature $\left(>70^{\circ} \mathrm{C}\right)$ confirmed the presence of many types of ligand environment in solution. For example, the ${ }^{13} \mathrm{C}$ NMR spectrum of the Nd(DTPA-PA $A_{2}$ ) complex in $\mathrm{D}_{2} \mathrm{O}$ at 100 $\mathrm{MHz}$ and $85^{\circ} \mathrm{C}$ showed nine signals in the carbonyl region ( $\delta$ 164-187), four sets (integral ratio $2: 2: 2: 1$ ) of propyl ${ }^{13} \mathrm{C}$ signals $(\delta=11.3-12.4,21.7-23.3$, and $42.6-45.0)$, and at least eleven partially overlapping signals for the other methylene groups. Upon cooling of the sample to $3^{\circ} \mathrm{C}$, substantial broadening occurred and most of the signals were very weak. A sample in $\mathrm{CD}_{3} \mathrm{OD}$ $(1: 1 \mathrm{v} / \mathrm{v})$ at $-30^{\circ} \mathrm{C}$ gave a spectrum in which each of the four signals of both the $\beta$-methylene and the methyl carbons of the propylamide group were split into two new signals (see Figure 1). Since the two propyl groups of the $\mathrm{Nd}^{\mathrm{Il}}$-bound ligand may be chemically different, this implies that at least four species are present in solution.

The methylene carbons of the diethylenetriamine group and the central glycine unit of the $\operatorname{Ln}\left(\mathrm{DTPA}_{\mathrm{P}} \mathrm{PA}_{2}\right)$ complexes $(\mathrm{Ln}=$ $\mathrm{La} \rightarrow \mathrm{Eu}$ ) gave, depending on the $\mathrm{L} \mathrm{n}^{\mathrm{III}}$ ion, broad signals or clusters of signals at roughly the same chemical shifts as those of the corresponding Ln(DTPA) complexes (see Table I), which suggests that there is similarity among the various species of the Ln(DTPA-PA $)_{2}$ complexes and between these complexes and

(24) Similar spectra have recently been observed for the diamagnetic La'11! and $\mathrm{Lu}^{\mathrm{III}}$ complexes of the ligand DTPA-bis(methoxyethylamide): White, D. H.; DeLearie, L. A.; Dunn, T. J.; Rizkalla, E. N.; Imura, H.; Choppin, G. R. Invest. Radiol. 1991, 26, S229.

(25) Desreux, J. F. Inorg. Chem. 1980, 19, 1319. 
Table I. Comparison of ${ }^{13} \mathrm{C}$ Chemical Shifts ${ }^{a}$ of $\operatorname{Ln}\left(\mathrm{DTPA}-\mathrm{PA}_{2}\right)^{b}$ with Those of $\operatorname{Ln}(\mathrm{DTPA})^{c}$ Complexes

\begin{tabular}{|c|c|c|c|}
\hline complex & $\mathrm{N}^{\prime} \mathrm{CH}_{2} \mathrm{CH}_{2} \mathrm{~N}^{3}$ & $\mathrm{~N}^{1} \mathrm{CH}_{2} \mathrm{CH}_{2} \mathrm{~N}^{3}$ & $\mathrm{~N}^{3} \mathrm{CH}_{2} \mathrm{CO}_{2}$ \\
\hline 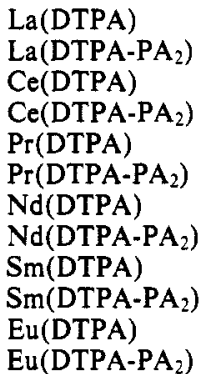 & $\begin{array}{l}59.11 \\
58.4-59.0 \\
46.06 \\
47.5 \\
30.18 \\
30.1 \\
32.60 \\
31.9 \\
58.23 \\
57.4-58.2 \\
99.48 \\
98.2\end{array}$ & $\begin{array}{l}57.71 \\
57.3 \\
36.10 \\
39.1-40.8 \\
13.45 \\
16.7 \\
24.59 \\
24.0 \\
56.68 \\
57.4-58.2 \\
114.82 \\
114.8\end{array}$ & $\begin{array}{l}66.57 \\
65.5 \\
53.17 \\
57.0-58.1 \\
45.99 \\
49.2 \\
52.88 \\
54.8-55.3 \\
66.69 \\
65.5 \\
96.07 \\
93.8-94.1\end{array}$ \\
\hline
\end{tabular}

${ }^{a}$ In ppm; in $\mathrm{D}_{2} \mathrm{O}$ at pD 7 and $73{ }^{\circ} \mathrm{C}$; internal standard tert-butyl alcohol $\left(\mathrm{CH}_{3}: 31.20 \mathrm{ppm}\right)$. The terminal and the middle $\mathrm{N}$-atoms are denoted as $\mathrm{N}^{1}$ and $\mathrm{N}^{3}$, respectively, ${ }^{b}$ Measured from $0.16 \mathrm{M}$ samples. At the chemical shifts given, several signals or a broad signal was observed. c Measured from samples obtained upon adding $\mathrm{Ln}$ "II to a $0.13 \mathrm{M}$ solution of $\mathrm{Li}_{5}$ (DTPA) in $\mathrm{D}_{2} \mathrm{O}$. Molar ratio $\mathrm{Ln}^{111} / \mathrm{DTPA}=0.7$.

Table II. Longitudinal ${ }^{13} \mathrm{C}$ Relaxation Times $\left(T_{1}\right)$ of $\mathrm{Nd}\left(\mathrm{DTPA}_{\mathrm{PA}}\right)$ and of La(DTPA-PA $\left.A_{2}\right)$ in $\mathrm{D}_{2} \mathrm{O}$ at $85^{\circ} \mathrm{C}$ and $50.3 \mathrm{MHz}$, Measured in $0.16 \mathrm{M}$ Solutions of the Complex

\begin{tabular}{|c|c|c|c|c|c|}
\hline$\delta(\mathrm{ppm})$ & $T_{1}(\mathrm{~s})$ & assgnt & $\delta(\mathrm{ppm})$ & $T_{1}(\mathrm{~s})$ & assgnt \\
\hline \multicolumn{6}{|c|}{$\mathrm{Nd}\left(\mathrm{DTPA}-\mathrm{PA}_{2}\right)$} \\
\hline 186.38 & 0.132 & $\mathrm{CO}$ & & 0.870 & $\alpha \cdot C \mathrm{H}_{2}$ (propyl) \\
\hline & 0.137 & $\mathrm{CO}$ & & & $\alpha-C \mathrm{H}_{2}$ (propyl) \\
\hline & 136 & $\mathrm{CO}$ & & 0.883 & $\alpha-C \mathrm{H}_{2}$ (propyl) \\
\hline & 160 & $\mathrm{CO}$ & & 36 & $\mathrm{CH}_{2} \mathrm{CH}_{2} \mathrm{~N}^{3}$ \\
\hline & 0.161 & $\mathrm{CO}$ & & 0.145 & $\mathrm{~N}^{1} \mathrm{CH}_{2} \mathrm{CH}_{2} \mathrm{~N}^{3}$ \\
\hline & 0.143 & $\mathrm{CO}$ & & 1.597 & $\beta-\mathrm{CH}_{2}$ (propyl) \\
\hline & 0 & $\mathrm{CO}$ & & 1.626 & $\beta-\mathrm{CH}_{2}$ \\
\hline & & $\mathrm{CO}$ & & 1.5 & $\mathrm{~B}-\mathrm{CH}_{2}$ \\
\hline & 0.13 & $\mathrm{CH}_{2} \mathrm{CO}$ & & 1.5 & $\beta-\mathrm{CH}_{2}$ \\
\hline & & $\mathrm{CH}_{2}$ & & & oropyl) \\
\hline & & & & & pyl) \\
\hline & & $\mathrm{CH}_{2}$ & & 2.8 & pyl) \\
\hline & & $\alpha-C_{2}$ (pro & & & $\gamma \cdot C H$ \\
\hline \multicolumn{6}{|c|}{$\mathrm{La}\left(\mathrm{DTPA}-\mathrm{PA}_{2}\right)$} \\
\hline & & $\mathrm{CO}$ & & 0.479 & \\
\hline & & $\mathrm{CO}$ & & 0.3 & $\mathrm{~N}^{1} \mathrm{CH}_{2} \mathrm{CH}_{2} \mathrm{~N}^{3 a}$ \\
\hline & & $\mathrm{CO}$ & & & $\mathrm{N}^{\prime} \mathrm{CH}_{2} \mathrm{CH}_{2} \mathrm{~N}^{3} a$ \\
\hline & 6.39 & $\mathrm{CO}$ & & & $\alpha-\mathrm{CH}_{2}$ (propyl) \\
\hline & 0.390 & $\mathrm{CH}_{2} \mathrm{C}$ & & 1.8 & $\beta-C H_{2}$ (propyl) \\
\hline 64.01 & 0.383 & $\mathrm{CH}_{2} \mathrm{CO}$ & 11.87 & 4.11 & $\gamma \cdot \mathrm{CH}_{3}$ (propyl) \\
\hline
\end{tabular}

${ }^{a}$ These assignments may be interchanged.

the $\operatorname{Ln}(\mathrm{DTPA})$ complexes. Attempts to fit the spectra to calculated ones for various models failed, due to the complexity of the spectra as a result of the large number of species present in solution, which hampered a full assignment of the spectra.

As a consequence of the partial double-bond character of the amide $\mathrm{C}-\mathrm{N}$ bond, the rotation around this bond is restricted, which could give rise to a 4 -fold splitting of the ${ }^{13} \mathrm{C}$ signals. However, in the ${ }^{13} \mathrm{C}$ and ${ }^{1} \mathrm{H}$ spectra of the free DTPA-PA 2 ligand, separate signals for the various rotamers were not observed, as probably fast rotations around the other bonds in this compound average out the chemical shift differences. Upon binding of the ligand to a paramagnetic $\mathrm{Ln}^{\mathrm{III}}$ ion, as a result of the reduced ligand flexibility and of paramagnetic effects on the chemical shifts, the rotation around the amide $\mathrm{C}-\mathrm{N}$ bonds might become slow on the ${ }^{13} \mathrm{C}$ NMR time scale. This could give rise to a 4-fold splitting of the various ${ }^{13} \mathrm{C}$ signals. However, the ${ }^{13} \mathrm{C}$ NMR spectrum of the NdIII complex of DTPA-bis(amide) (DTPA$A_{2}$ ) for which the rotamers are identical, showed an analogous splitting of the various signals; at $85^{\circ} \mathrm{C}$, for example, eight carbonyl signals were observed between 162 and $188 \mathrm{ppm}$. Therefore, it can be concluded that slow rotations around the amide $\mathrm{C}-\mathrm{N}$ bonds cannot explain the occurrence of multiple sets of signals in the ${ }^{13} \mathrm{C}$ NMR spectra of the Ln-DTPA-PA 2 complexes.
NdIII-Induced Relaxation Rate Enhancements. Among the lighter $\mathrm{Ln}^{\mathrm{III}}$ ions $(\mathrm{Ln}=\mathrm{Ce} \rightarrow \mathrm{Eu}) \mathrm{Nd}^{\text {III }}$ has the longest electron relaxation times ${ }^{26}$ and, therefore, this lanthanide was selected for a study of the coordination of the DTPA-PA 2 ligand by means of ${ }^{13} \mathrm{C}$ NMR longitudinal relaxation rates. The measurements were performed at $85^{\circ} \mathrm{C}$ and $50.3 \mathrm{MHz}$. From the variabletemperature spectra of the Nd(DTPA-PA $)$ complex (see above), it can be concluded that under these conditions fast exchange on the NMR time scale occurs between several ligand nuclei, which probably can be ascribed to exchange between species. Assuming that there are two species $A$ and $B$, which are in fast exchange on the NMR time scale, the observed longitudinal relaxation rate of a nucleus $\left(1 / T_{1, \text { obs }}\right)$ is given by ${ }^{27,28}$

$$
1 / T_{1, \mathrm{obs}}=f_{\mathrm{A}} / T_{1, \mathrm{~A}}+f_{\mathrm{B}} / T_{1, \mathrm{~B}}
$$

where $T_{1, \mathrm{~A}}$ and $T_{1, \mathrm{~B}}$ are the intrinsic relaxation times in the absence of exchange and $f_{\mathrm{A}}$ and $f_{\mathrm{B}}$ are the molar fractions of $\mathrm{A}$ and $\mathrm{B}$. For exchange between more than two species analogous expressions can be derived. For each isomer the relaxation rate can be related to its structure via the reduced Solomon-Bloembergen equation: 26,29

$$
1 / T_{1}={ }^{4} /{ }_{3}\left(\mu_{0} / 4 \pi\right)^{2}\left(\mu^{2} \gamma^{2} \beta^{2} T_{1, \mathrm{e}} / r^{6}\right)
$$

Here $\mu_{0} / 4 \pi$ is the magnetic permeability under vacuum, $\mu$ is the effective magnetic moment of the lanthanide ion, $\gamma$ is the magnetogyric ratio, $\beta$ is the Bohr magneton, $T_{1, \mathrm{e}}$ is the electron spin relaxation time, and $r$ is the distance between the ${ }^{13} \mathrm{C}$ nucleus in question and the lanthanide ion.

The relaxation rates obtained for the various ${ }^{13} \mathrm{C}$ signals are compiled in Table II. It can be seen that the magnitudes of the relaxation rates for corresponding nuclei of the various species are about the same. In order to obtain a correction for diamagnetic

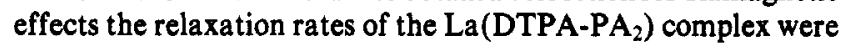
measured as well (see Table II). In Table III the ranges of corrected relaxation rates for the various nuclei are given. It has been shown that $T_{1 \mathrm{e}}$ usually is rather independent of the ligation of the $\mathrm{Ln}^{\mathrm{III}}$ cation. ${ }^{30,32}$ For example, the values of $T_{1 \mathrm{e}}$ for Gd(DTPA) ${ }^{2-}$ and Gd(DTPA-bisamide) as obtained from solution EPR measurements are very similar. ${ }^{33}$ For lanthanides other than $\mathrm{Gd}$, large deviations from $T_{1 \mathrm{e}}$ would be expected only for complexes with very rigid and symmetric macrocyclic ligands. ${ }^{34}$ By use of the data reported by Alsaadi et al. on NdII complexes of DTPA and related amino polycarboxylate ligands, ${ }^{30} T_{1, e}$ for the Nd(DTPA-PA $)$ complexes at $85^{\circ} \mathrm{C}$ is estimated to be 0.9 $\times 10^{-13} \mathrm{~s}$. Then "averaged" distances $r$ were calculated from the corrected relaxation rates and eq 2 . The distances obtained are given in Table III. From these distances it can be concluded that the DTPA-PA 2 ligand is bound to the $\mathrm{Ln}^{\mathrm{III}}$ ion via the three carboxylate groups (in a monodentate fashion), the two amide oxygens, and the three $\mathbf{N}$ atoms of the diethylenetriamine unit. The presence of significant amounts of isomers, in which one of the carboxylate or amide groups is not coordinated to $\mathrm{Ln}^{\mathrm{III}}$, can be excluded because, according to eq 2 , this would have been reflected in relative large values for $1 / T_{1}$ for the concerning ${ }^{13} \mathrm{C}$ nuclei. The structure of the Nd(DTPA-PA $)$ complex is analogous to those of the previously reported Nd(DTPA) complex in solution ${ }^{5}$ and the solid-state structure of Gd(DTPA-EA $\left.)_{2}\right)^{12}$ For com-

(26) Dwek, R. A. Nuclear Magnetic Resonance in Biochemistry; Clarendon Press: Oxford, U.K., 1973.

(27) Leigh, J. S., Jr. J. Magn. Reson. 1971, 4, 308.

(28) McLaughlin, A. C.; Leigh, J. S., Jr. J. Magn. Reson. 1973, 9, 296.

(29) Reuben, J.; Fiat, D. J. Chem. Phys. 1969, 51, 4918.

(30) Alsaadi, B. M.; Rossotti, F. J. C.; Williams, R. J. P. J. Chem. Soc., Dalton Trans. 1980, 2151.

(31) Alsaadi, B. M.; Rossotti, F. J. C.; Williams, R. J. P. J. Chem. Soc, Dalton Trans. 1980, 2147.

(32) Burns, P. D.; LaMar, G. N. J. Magn. Reson. 1982, 46, 61.

(33) Geraldes, C. F. G. C. Unpublished results.

(34) Sherry, A. D.; Brown, R. D., III; Geraldes, C. F. G. C.; Koenig, S. H.; Kuan, K.-T.; Spiller, M. Inorg. Chem. 1989, $28,620$. 
Table III. Nd'II-Induced ${ }^{13} \mathrm{C}$ Relaxation Rate Enhancements $\left(1 / T_{1}\right)$ and NdIILC Distances in the Isomers of Nd(DTPA-PA $)$ : Comparison with Distances in the Nd(DTPA) ${ }^{2-}$ Complex ${ }^{5}$ and in the Solid-State Structure of Gd(DTPA-EA $\left.)_{2}\right)^{12}$

\begin{tabular}{|c|c|c|c|c|c|}
\hline \multirow[b]{2}{*}{ nucleus } & \multicolumn{2}{|c|}{$1 / T_{1}\left(s^{-1}\right)^{a}$} & \multicolumn{3}{|c|}{$r(\mathrm{~A})$} \\
\hline & $\mathrm{Nd}\left(\right.$ DTPA-PA $\left.{ }_{2}\right)$ (soln) & $\mathrm{Nd}(\mathrm{DTPA})(\mathrm{soln})^{b}$ & Nd(DTPA-PA $A_{2}$ (soln) & $\operatorname{Nd(DTPA)~(soln)~}{ }^{b}$ & $\operatorname{Gd}\left(D T P A-E A_{2}\right)(X-r a y)$ \\
\hline$C O$ & $6.07-7.48$ & $5.99-6.53$ & $3.08-3.19$ & $3.15-3.20$ & $3.25-3.31$ \\
\hline $\mathrm{CH}_{2} \mathrm{CO}$ & $4.40-5.39$ & $e$ & $3.25-3.37$ & $e$ & $3.40-3.56$ \\
\hline $\mathrm{N}^{\prime} \mathrm{CH}_{2} \mathrm{CH}_{2} \mathrm{~N}^{3}$ & $3.96-4.02$ & 5.89 & $3.42-3.43$ & 3.21 & $3.46-3.54$ \\
\hline $\mathrm{N}^{\prime} \mathrm{CH}, \mathrm{CH}_{2} \mathrm{~N}^{3}$ & $4.42-4.47$ & 3.61 & $3.36-3.36$ & 3.48 & $3.46-3.51$ \\
\hline$\alpha \cdot C \mathrm{H}_{2}$ (propyl) & $0.24-0.28$ & & $5.33-5.47$ & & $5.13-5.23$ \\
\hline$\beta-C H_{2}$ (propyl) & $0.06-0.09$ & & $6.46-6.89$ & & $5.26-6.45$ \\
\hline$\gamma-\mathrm{CH}_{3}$ (propyl) & $0.09-0.15$ & & $5.91-6.44$ & & \\
\hline
\end{tabular}

${ }^{a}$ Ranges for the signals of the various isomers. Corrected for diamagnetic contributions by subtracting the relaxation rates of the corresponding $\mathrm{La}^{111}$ complex. Soln $=$ solution. ${ }^{b}$ Calculated from the corrected relaxation rates and eq $2 .^{c}$ Reference $5 .{ }^{d}$ Reference $12 .{ }^{e}$ Not measured, because of overlapping signals.

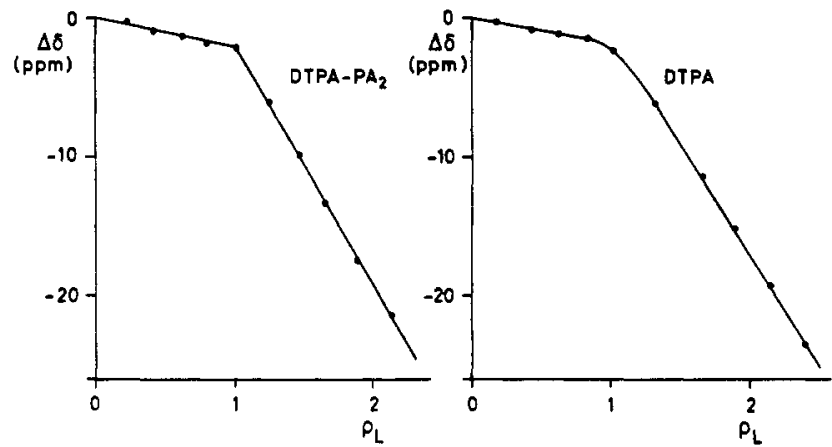

Figure 2. Plot of the Dy ${ }^{11}$-induced water ${ }^{17} O$ shift versus the molar ratio Dy'll' /organic ligand $\left(\rho_{\mathrm{L}}\right)$ for $0.05 \mathrm{M}$ solutions of DTPA-PA 2 and DTPA in $\mathrm{D}_{2} \mathrm{O}$ at $25^{\circ} \mathrm{C}$.

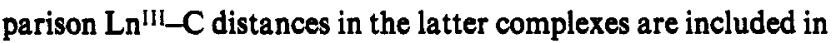
Table III. It can be seen that they are in agreement with the distances obtained now for the Nd(DTPA-PA $)$ complex. The inversion of the three $\mathrm{N}$ atoms in the diethylenetriamine backbone of DTPA-PA ${ }_{2}$ is precluded upon binding to NdIII. Then these $\mathbf{N}$ atoms are chiral, and in principle eight enantiomeric forms (four diastereomeric pairs) are possible for the $\mathrm{L} \mathrm{n}^{\mathrm{III}}$-bound ligand, which explains the large number of ${ }^{13} \mathrm{C}$ NMR signals observed for these complexes.

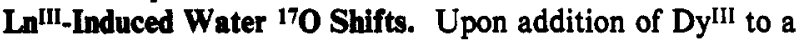
solution of DTPA-PA $A_{2}$ in $\mathrm{D}_{2} \mathrm{O}$, the water ${ }^{17} \mathrm{O}$ shift decreases

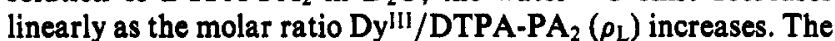
exchange of water between the DyllI complex and the bulk is fast on the ${ }^{17} \mathrm{O} N \mathrm{NR}$ time scale. At $\rho_{\mathrm{L}}=1.0$, a steep increase in the magnitude of the (negative) induced shift occurred; the slope of the line at $\rho_{\mathrm{L}}>1.0$ was 8.4 times as large as that of the line at $\rho_{\mathrm{L}}<1.0$ and equal to the slope of the line, obtained when the experiment was performed in the absence of DTPA-PA 2 (see Figure 2). The sharp change in the slope of the curve at $\rho_{L}=$ 1.0 is in agreement with the high stability constants of the LnDTPA-PA 2 complexes $(\log K=16.23$ for $\ln =\mathrm{Gd}) .{ }^{11}$ Previously, we have shown that the Dylll-induced ${ }^{17} \mathrm{O}$ water shift is almost independent of the other ligands coordinated to the DyIII ion. ${ }^{35-38}$ Consequently the slope of the plot of the Dy'll-induced shift versus the molar ratio DyIII/water $\left(\rho_{w}\right)$ can be used to determine the hydration numbers of DyIII complexes. If it is assumed that in the absence of organic ligands DylI in $\mathrm{D}_{2} \mathrm{O}$ is coordinated by 8 or 9 water ligands, then it can be concluded that one Dy III-bound water is present in the Dy(DTPA-PA $)$ complexes. The total coordination number is therefore 9 , which is the most common value for aqueous systems with this type of ligands. The plot of

(35) Vijverberg, C. A. M.; Peters, J. A.; Kieboom, A. P. G.; van Bekkum, H. Recl. Trav. Chim. Pays-Bays 1980, 99, 403.

(36) Peters, J. A.; Nieuwenhuizen, M.S.; Raber, D. J. J. Magn. Reson. 1985, 65,417 .

(37) Nieuwenhuizen, M. S.; Peters, J. A.; Sinnema, A.; Kieboom, A. P. G. van Bekkum, H. J. Am. Chem. Soc. 1985, 107, 12.

(38) Alpoim, M. C.; Urbano, A. M.; Geraldes, C. F. G. C.; Peters, J. A. J. Chem. Soc., Dalton Trans. 1992, 463. the Dylli-induced shift verus $\rho_{L}$ for the system DyIII-DTPA (see Figure 2) is analogous, with exception of the change of the slope of the curve at $\rho_{\mathrm{L}}=1.0$, which was not sharp but gradual. The stability constants of the $\operatorname{Ln}(\mathrm{DTPA})$ complexes $(\log K=22.26$ for $\mathrm{Ln}=\mathrm{Gd})^{11}$ are however much higher than those for the DTPA$\mathbf{P A}_{2}$ complexes. The different shape of the curve around $\rho_{\mathrm{L}}=$ 1 has to be ascribed to the binding of Dyill ions to the carboxylate groups in the second coordination sphere of the [Dy(DTPA)]2complex, which has been shown to occur previously.5 Apparently, the affinity of the neutral Dy(DTPA-PA $)$ complex for DyIII cations is much smaller.

In order to obtain the number of inner-sphere water molecules in the other $\operatorname{Ln}\left(\mathrm{DTPA}-\mathrm{PA}_{2}\right.$ ) complexes, a more rigorous treatment of the $\mathrm{Ln}^{\mathrm{III}}$-induced water ${ }^{17} \mathrm{O}$ shifts is required. The induced shifts $(\Delta)$ are a combination of diamagnetic $\left(\Delta_{d}\right)$, contact $\left(\Delta_{c}\right)$, and pseudocontact shifts $\left(\Delta_{p}\right)$. The value of $\Delta_{d}$ can be estimated from an interpolation of the induced shifts for $\mathrm{La}^{\mathrm{III}}$ and $\mathrm{Lu}^{\mathrm{III}}$. The contact contribution results from a through-bond transmission of unpaired spin density of the $\mathrm{Ln}^{\mathrm{III}}$ cation in question, whereas the pseudocontact shift arises from a through-space dipolar interaction between the magnetic moments of the unpaired electrons of the $\mathrm{L} n^{\mathrm{III}}$ ion and the ${ }^{17} \mathrm{O}$ nucleus. Both $\Delta_{c}$ and $\Delta_{p}$ can be written as the product of a term that is characteristic of the $\mathrm{L} \mathrm{n}^{\mathrm{III}}$ ion but independent of the complex structure $\left(\left\langle S_{z}\right\rangle\right.$ and $C^{D}$, respectively) and a second term that is characteristic of the complex but that is independent of the $\mathrm{L} n^{\mathrm{III}}$ ion ( $F$ and $G$, respectively): 39,40

$$
\Delta^{\prime}=\Delta-\Delta_{\mathrm{d}}=\Delta_{\mathrm{c}}+\Delta_{\mathrm{p}}=\left\langle S_{z}\right\rangle F+C^{D} G
$$

Values for $\left\langle S_{z}\right\rangle$ and $C^{D}$ are tabulated in the literature. ${ }^{39-43}$ When the various $\mathrm{Ln}^{\mathrm{III}}$ complexes are isostructural, eq 3 can be rearranged in a linear form: ${ }^{44}$

$$
\Delta^{\prime} / C^{D}=\left\langle S_{z}\right\rangle F / C^{D}+G
$$

So, when a series of $\mathrm{L} n^{\mathrm{III}}$ complexes yields a linear plot of $\Delta^{\prime} / C^{D}$ versus $\left\langle S_{z}\right\rangle / C^{D}$, this is an indication that they are isostructural. 44,45

The water ${ }^{17} \mathrm{O}$ shifts obtained for the various $\mathrm{Ln}-\mathrm{DTPA}-\mathrm{PA}_{2}$ systems at $73^{\circ} \mathrm{C}$ were extrapolated to $\rho_{w}=1$ (see Table IV). The values obtained correspond to $n \Delta$, where $n$ is the number of $\mathrm{Ln}^{\mathrm{III}}$ bound waters in the concerning complex. A plot of these shifts according to eq 4 gives a straight line (see Figure 3 ), which shows that no change of the number of inner-sphere waters occurs along the lanthanide series. By means of a multiple regression method ${ }^{46}$ the values of $n F$ and $n G$ were determined to be -68 and 8.56 ,

(39) Golding, R. M.; Halton, M. P. Aust. J. Chem. 1972, $25,2577$.

(40) Bleaney, B. J. Magn. Reson. 1972, 8, 91.

(41) Bleaney, B.; Dobson, C. M.; Levine, B. A.; Martin, R. B.- Williams, R. J. P.: Xavier, A. V. J. Chem. Soc., Chem. Commun. 1972, 791.

(42) Golding, R. M.; Pyykkö, P. Mol. Phys. 1973, 26, 1389.

(43) Pinkerton, A. A.; Rossier, M.; Spiliadis, S. J. Magn. Reson. 1985, 64, 420.

(44) Reuben, J. J. Magn. Reson. $1982,50,233$.

(45) Peters, J. A. J. Magn. Reson. 1986, 68, 240.

(46) Reilley, R. N.; Good, B. W.; Allendoerfer, R. D. Anal. Chem. 1976, 48 , 1446. 
Table IV. Lanthanide-Induced Water ${ }^{17} \mathrm{O}$ Shifts (ppm) for $0.16 \mathrm{M}$ $\mathrm{Ln}^{\prime \prime \prime}\left(\mathrm{DTPA}-\mathrm{PA}_{2}\right.$ ) Complexes in $\mathrm{D}_{2} \mathrm{O}$ at $\mathrm{pD} 7$ and $73^{\circ} \mathrm{C}$

\begin{tabular}{lclc}
\hline $\mathrm{Ln}^{\mathrm{II}}$ & $\delta(\mathrm{ppm})^{a}$ & $\mathrm{Ln}^{11 \prime}$ & $\delta(\mathrm{ppm})^{a}$ \\
\hline $\mathrm{La}$ & 338 & $\mathrm{Dy}$ & -1960 \\
$\mathrm{Ce}$ & 381 & $\mathrm{Ho}$ & -1051 \\
$\mathrm{Pr}$ & 511 & $\mathrm{Er}$ & -238 \\
$\mathrm{Nd}$ & 648 & $\mathrm{Tm}$ & 464 \\
$\mathrm{Sm}$ & 297 & $\mathrm{Yb}$ & 314 \\
$\mathrm{Eu}$ & -320 & $\mathrm{Lu}$ & 421 \\
$\mathrm{~Tb}$ & -1901 & &
\end{tabular}

${ }^{a}$ The shifts were obtained using plots analogous to that given in Figure 2. The values are extrapolated to a molar ratio of $L n^{\prime I I} /$ water $\left(\rho_{w}\right)=$ 1. The relative errors are $5 \%$.

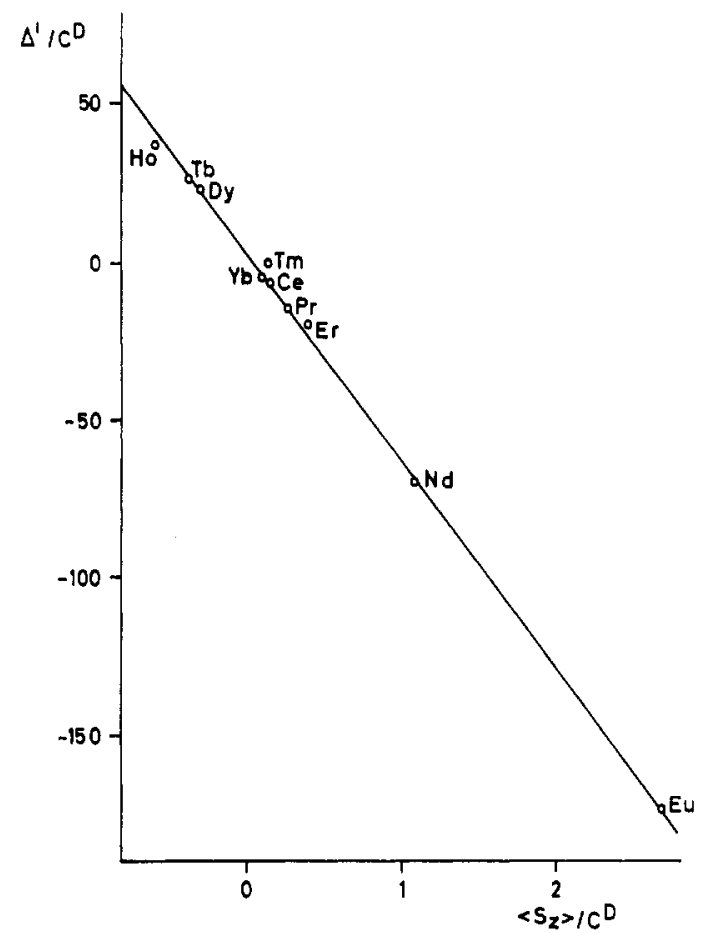

Figure 3. Plot of $\Delta^{\prime} / C^{D}$ versus $\left\langle S_{z}\right\rangle / C^{D}$ for the ${ }^{17} \mathrm{O}$ signal in the $\mathrm{Ln}-$ DTPA-PA $A_{2}$ system at $73^{\circ} \mathrm{C}$.

respectively. Previously, it has been observed that the values of $F$ for $\mathrm{Ln}^{111}$-bound oxygens are in a rather small range of $-70 \pm$ 11 at $73{ }^{\circ} \mathrm{C} .35-37$ Therefore from the value of $n F$ obtained it can be concluded that $n=1$ for all Ln ${ }^{\text {III }}-D T P A-P A_{2}$ complexes, which is in agreement with the results of previous fluorescence and relaxivity measurements. ${ }^{6}$

Chemical Exchange between the Various $\operatorname{Ln}\left(\mathrm{DTPA}-\mathrm{PA}_{2}\right.$ ) Isomers. From the results of the ${ }^{13} \mathrm{C}$ relaxation rate measurements and the $\mathrm{Ln}^{\mathrm{III}}$-induced water ${ }^{17} \mathrm{O}$ measurements it can be concluded that the Ln(DTPA-PA ${ }_{2}$ ) complexes are nine-coordinate with DTPA-PA $A_{2}$ bound in an octadentate fashion and with one water molecule in the first coordination sphere. The coordination polyhedron of nine-coordinate $\mathrm{Ln}^{\mathrm{III}}$ compounds can usually be described by a distorted tricapped trigonal prism or by a distorted monocapped square antiprism. ${ }^{47}$ These two geometries are closely related ${ }^{48}$ and often a particular structure can be described by both geometries equally well. The X-ray structure of the Gd(DTPA-EA ${ }_{2}$ ) complex can be best described by a tricapped trigonal prism, ${ }^{12}$ and therefore, we will discuss the solution structure also in terms of this polyhedron. A similar discussion can, however, be given for a monocapped square antiprism.

An inspection of molecular models shows that DTPA-PA 2 can only be arranged around a $\mathrm{Ln}^{\mathrm{III}}$ ion when the middle nitrogen

(47) Palenik, G. J. In Systematics and Properties of the Lanthanides; Sinha, S. P., Ed.; NATO ASI Series C; Kluwer: Dordrecht, The Netherlands, 1983; Vol. 109, Chapter 5.

(48) Favas, M. C.; Kepert, D. L. Prog. Inorg. Chem. 1981, 28, 309.
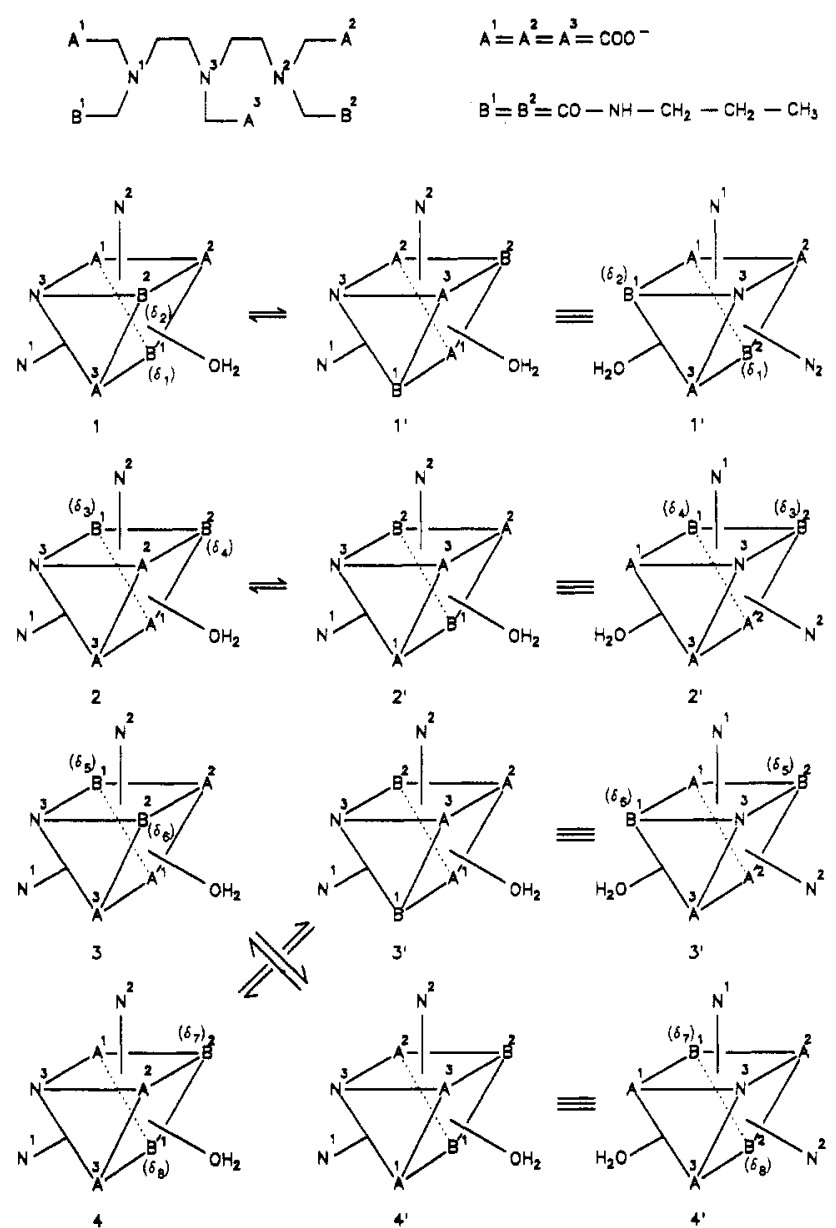

Figure 4. Coordination polyhedrons of the eight enantiomers of the $\mathrm{Ln}$ (DTPA-PA ${ }_{2}$ ) complex, assuming that the geometry is a tricapped trigonal prism. The interconversions via the "wagging" process are indicated. Between parentheses are fictitious chemical shifts of corresponding nuclei in the amide groups (see text). It should be noted that no discrimination can be made between $A^{1}$ and $A^{2}, B^{1}$ and $B^{2}$, and $N^{1}$ and $N^{2}$. These groups are labeled in order to be able to follow them during the rearrangements.

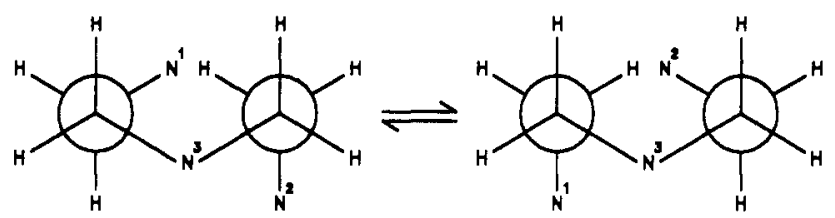

Figure 5. Conformational interconversion in the diethylenetriamine backbone of $\operatorname{Ln}\left(\mathrm{DTPA}-\mathrm{PA}_{2}\right)$ complexes.

atom $\left(\mathrm{N}^{3}\right.$; see Figure 4$)$ is on a "prismatic" position, whereas the terminal $\mathrm{N}$-atoms $\left(\mathrm{N}^{1}\right.$ and $\mathrm{N}^{2}$ ) and the water ligand have to occupy the capping positions. The eight possible enantiomers of the bound ligand give rise to the complex geometries depicted in Figure 4. Geometries $\mathbf{1}^{\prime}-\mathbf{4}^{\prime}$ are the mirror images of 1-4. Thus for each nucleus in the DTPA-PA 2 ligand in principle four signals can be expected. The paramagnetic properties of the $\mathrm{Ln}^{\mathrm{III}}$ ion magnify the chemical shift differences between these signals. This is in agreement with the observation of, for example, eight peaks for the methylene carbons of the two propyl groups of the Nd-DTPA-PA 2 complex at $-30^{\circ} \mathrm{C}$. The molecular models also suggest that two different staggered ethane conformations are possible on either side of the middle $\mathrm{N}$-atom $\left(\mathrm{N}^{3}\right)$. For the corresponding $\operatorname{Ln}(\mathrm{DTPA})$ complexes, it has been shown that a "wagging" between these conformations occurs (Figure 5). This process requires a rearrangement of the coordination polyhedron, during which the groups $A^{1} / B^{1}$ and $A^{2} / B^{2}$ interconvert between a rectangular and a triangular edge of the tricapped trigonal prism (see Figure 4). For isomers 1 and 2 the "wagging" causes 
an interconversion with the mirror images $\mathbf{1}^{\prime}$ and $\mathbf{2}^{\prime}$, respectively. Structure 3, however, is interconverting with the mirror image of $4\left(4^{\prime}\right)$, and similarly 4 is exchanging with $3^{\prime}$ via the "wagging" process. This leads to a reduction of the number of NMR signals, when these interconversions become rapid on the NMR time scale. Consider, for example, corresponding nuclei in the amide groups $\mathbf{B}^{\prime}$ and $\mathbf{B}^{2}$. If these nuclei have chemical shifts $\delta_{1}$ and $\delta_{2}$, respectively, in isomer 1 , then in $\mathbf{1}^{\prime}$ the chemical shifts have been interchanged to $\delta_{2}$ and $\delta_{1}$, respectively (see Figure 4 ). When the exchange is fast on the NMR time scale, these nuclei will coalesce to a single signal with chemical shift $\left(\delta_{1}+\delta_{2}\right) / 2$. Similar phenomena occur upon exchange between 2 and $2^{\prime}$. For isomers 3 and 4 the situation is different. If in isomer 3 the amide nuclei $B_{1}$ and $B_{2}$ have chemical shifts $\delta_{5}$ and $\delta_{6}$, respectively, then after the rearrangement to $4^{\prime}$ the chemical shifts will have different values, say $\delta_{7}$ and $\delta_{8}$. So in the case of rapid exchange two new signals are obtained at $\left(\delta_{5}+\delta_{7}\right) / 2$ and $\left(\delta_{6}+\delta_{8}\right) / 2$, respectively. Since 4 is the mirror image of $4^{\prime}$, the chemical shifts of $B_{1}$ and $\mathbf{B}_{2}$ in the former isomer are $\delta_{8}$ and $\delta_{7}$, respectively. Similarly, it can be seen that the shifts of these nuclei in $3^{\prime}$ are $\delta_{6}$ and $\delta_{5}$. The exchange between 4 and $3^{\prime}$ leads then again to signals at $\left(\delta_{5}+\right.$ $\left.\delta_{7}\right) / 2$ and $\left(\delta_{6}+\delta_{8}\right) / 2$, in the case of fast exchange on the NMR time scale. Thus the two signals of the interconverting couple $3 \rightleftharpoons 4^{\prime}$ are coinciding with those of the couple $4 \rightleftarrows 3^{\prime}$. Altogether, the number of signals for the nuclei concerned in $B_{1}$ and $B_{2}$ decreases from 8 to 4 upon going from the slow to the fast exchange region of the "wagging" process. This is in agreement with the observations in the ${ }^{13} \mathrm{C}$ spectra between -30 and $+70{ }^{\circ} \mathrm{C}$ (see Figure 2). From the coalescence temperatures it can be estimated that $\Delta G^{*}{ }_{283}=53 \mathrm{~kJ} / \mathrm{mol}$ for this rearrangement. This is about the same as the value found for $\operatorname{Ln}(D T P A)$ complexes (for example, $\operatorname{Pr}(\text { DTPA })^{2-}: \Delta G^{\ddagger}{ }_{298}=56.5 \mathrm{~kJ} / \mathrm{mol}$ ). ${ }^{16}$ Replacement of two carboxylate groups by the relatively weak coordinating amide groups has no influence on the activation barrier. Probably, this barrier is determined by the eclipsing in the ethylene bridges in the diethylenetriamine backbone at the transition state. This is in line with the higher barriers observed for a similar process in lanthanide complexes of macrocyclic ligands, such as DOTA, ${ }^{25}$ where two more ethylene groups are eclipsing in the transition state.

The chemical shift differences between corresponding nuclei in the various isomers are considerably smaller in the diamagnetic $\mathrm{La}^{\prime \prime \prime}$ and $\mathrm{Lu}^{\prime \prime \prime}$ complexes of DTPA-PA $\mathrm{A}_{2}$. This allowed the identification of a dynamic process with a higher barrier. Upon increasing of the temperature from 10 to $90^{\circ} \mathrm{C}$, a substantial increase of the line widths was observed in the ${ }^{13} \mathrm{C}$ spectra of these complexes, and some of the signals were coalescing. If it is assumed that exchange associated with the lines that broaden but do not coalesce in the temperature range mentioned is slow on the NMR time scale, then the exchange rate $(k)$ can be calculated from the observed line widths $\left(\Delta \nu_{1 / 2}\right)$ with ${ }^{49}$

$$
k=\pi\left(\Delta \nu_{1 / 2}-\Delta \nu_{1 / 2}(0)\right)
$$

where $\Delta \nu_{1 / 2}(0)$ is the line width in the absence of exchange. Then from the slope and the intercept of an Eyring plot, $\Delta H^{*}$ and $\Delta S^{*}$ can be calculated. In Figure 6 the Eyring plot for one of the carboxylate signals is given as an example. Using the line widths of eight ${ }^{13} \mathrm{C}$ signals of the La(DTPA-PA $A_{2}$ ) complex and five signals of the Lu(DTPA-PA $)$ complex, the activation parameters compiled in Table $\mathrm{V}$ were obtained. These values were in good agreement with the $\Delta G^{*}$ values estimated from the coalescence temperatures of some other lines in the spectra. The difference in the parameters between the $\mathrm{La}^{\mathrm{III}}$ and the $\mathrm{Lu}^{\mathrm{III}}$ complex is negligible. These dynamic phenomena were independent of the complex concentration $(0.02-0.16 \mathrm{M})$, which indicates that the concerning complex rearrangements are intramolecular. The

(49) Sandström, J. Dynamic NMR Spectroscopy; Academic Press: London, 1982.

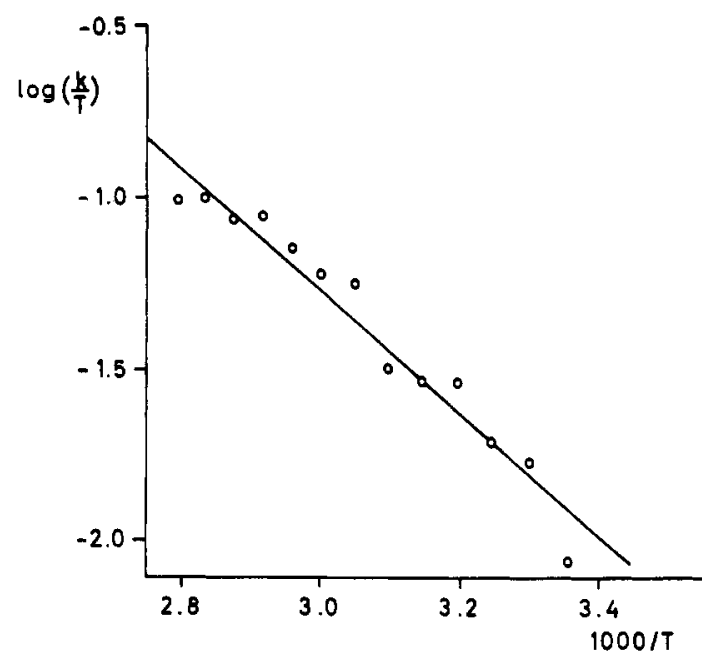

Figure 6. Eyring plot for the rearrangements in the La(DTPA-PA $)$ complex. The data were obtained at $100.6 \mathrm{MHz}$ from the line widths of the carobxylate signal at $182.8 \mathrm{ppm}$.

Table V. Kinetic Data for Rearrangements in Ln(DTPA-PA $A_{2}$ ) Complexes ${ }^{a}$

\begin{tabular}{|c|c|c|c|c|c|}
\hline dynamic process & Ln & $\begin{array}{c}\Delta G^{*}{ }_{283} \\
(\mathrm{~kJ} / \mathrm{mol})\end{array}$ & $\begin{array}{c}\Delta H^{*} \\
(\mathrm{~kJ} / \mathrm{mol})\end{array}$ & $\begin{array}{c}\Delta S^{*} \\
(\mathrm{~J} / \mathrm{mol} \mathrm{K})\end{array}$ & $k_{2 \times 3}\left(\mathrm{~s}^{1}\right)$ \\
\hline racemization at & $\mathrm{La}^{b}$ & $71(1)$ & $47(8)$ & $-84(25)$ & 0.7 \\
\hline$N^{1}, N^{2}$ & $\mathrm{Lu}^{c}$ & $67(1)$ & $42(8)$ & $-88(20)$ & 2.4 \\
\hline $\begin{array}{l}\text { racemization at } \\
N^{3} \text { ("wagging") }\end{array}$ & $\mathrm{Nd}^{d}$ & $53(1)$ & & & $3.5 \times 10^{2}$ \\
\hline $\begin{array}{l}\text { rotation } \mathrm{COO} \\
\text { groups }\end{array}$ & $\mathrm{La}^{e}$ & $<43$ & & & $>9.6 \times 10^{3}$ \\
\hline
\end{tabular}

${ }^{a}$ Measured with $0.16 \mathrm{M}$ solutions in $\mathrm{D}_{2} \mathrm{O} .{ }^{b}$ From ${ }^{13} \mathrm{CNMR}$ line shapes $(100.6 \mathrm{MHz})$. Average of the results of eight lines. Exchange rates are estimated from extrapolations of Eyring plots. ' As in $b$. Average of the results of five lines. ${ }^{d}$ From coalescence temperatures of ${ }^{13} \mathrm{CNMR}$ signals (at $100.6 \mathrm{MHz}$ ). ${ }^{e}$ From ${ }^{17} \mathrm{O} \mathrm{NMR}$ measurements (at $54.2 \mathrm{MHz}$; see text).

barriers obtained are somewhat higher than the difference in stability between corresponding octadentate and pentadentate bound polyamino polycarboxylates as estimated from their stability constants. ${ }^{50}$ Therefore, this barrier can be explained by inversion of the terminal diethylenetriamine $\mathrm{N}$-atoms $\left(\mathrm{N}_{1}\right.$ and $\mathrm{N}_{2}$ ), which requires partial decoordination of the ligand, thus by the exchanges $1 \rightleftarrows 3,1^{\prime} \rightleftarrows 3^{\prime}, 1 \rightleftarrows 4,1^{\prime} \rightleftarrows 4^{\prime}, 2 \rightleftarrows 3,2^{\prime} \rightleftarrows 3^{\prime}$, $2 \rightleftarrows 4$, and $2^{\prime} \rightleftarrows 4^{\prime}$ (see Figure 4).

In the diamagnetic $\operatorname{Ln}$ (DTPA) complexes no line broadening was observed in the ${ }^{13} \mathrm{C}$ spectra upon increasing the temperature from 20 to $90^{\circ} \mathrm{C}$, which nicely demonstrates the difference in coordination strength between a carboxylate and an amide function.

A sample of a $\mathrm{La}\left(\mathrm{DTPA}-\mathrm{PA}_{2}\right.$ ) complex in which the carboxylate groups were about $5 \%$ enriched with ${ }^{17} \mathrm{O}$ showed at 54.2 $\mathrm{MHz}$ and $90^{\circ} \mathrm{C}$ an ${ }^{17} \mathrm{O}$ spectrum with broad lines at 280 and $290 \mathrm{ppm}$ with an integral ratio of 1:2. These lines are assigned to the middle and the terminal carboxylate groups, respectively. Since the carboxylate groups are bound to the $\mathrm{Ln}^{\text {III }}$ ion in a monodentate fashion, the oxygens within each carboxylate group are chemically inequivalent. Apparently, the exchange between these oxygen atoms is rapid on the ${ }^{17} \mathrm{O}$ NMR time scale as a result of rotation. The slow-exchange region could not be reached by cooling to $10^{\circ} \mathrm{C}$. In ${ }^{17} \mathrm{O}$ spectra of $\mathrm{Al}^{111}$ complexes of various carboxylates the carboxylate rotation has been observed to be slow on the NMR time scale. ${ }^{51}$ In those cases peaks were observed at about 220 and 300 ppm for the Allil-bound oxygens and the

(50) Martell, A. E.; Smith, R. M. Critical Stability Constants; Plenum Press: New York, 1977 and 1982; Vols. 3 and 5.

(51) Venema, F. R.; Peters, J. A.; van Bekkum, H. J. Chem. Soc., Dalton Trans. 1990, 2137. 
noncoordinated oxygens of the carboxylate groups, respectively. If we assume that, under slow-exchange conditions, the chemical

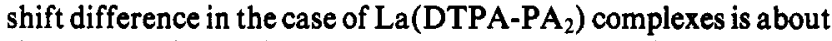
the same and that the coalescence temperature of these signals is below $10^{\circ} \mathrm{C}$, then using standard methods ${ }^{49}$ the upper limit of $\Delta G^{*}$ for the rotation of the carboxylate groups in the La(DTPA-PA ${ }_{2}$ ) complex can be estimated to be $43 \mathrm{~kJ} / \mathrm{mol}$.

\section{Conclusions}

In conclusion we have shown that DTPA-PA 2 is coordinated to $\mathrm{Ln}^{\text {III }}$ ions in an octadentate fashion via the three $\mathrm{N}$ atoms of the diethylenetriamine backbone, three carboxylate oxygens, and the two amide oxygens. All $\mathrm{Ln}^{\mathrm{III}}$ complexes contain one innersphere water molecule. The four possible diastereomeric pairs all occur in aqueous solution. This is, for example, illustrated by the observation of eight signals for the $\beta$ - and for the $\gamma-{ }^{13} \mathrm{C}$ nuclei of the two propyl groups of the Nd(DTPA-PA $\left.A_{2}\right)\left(\mathrm{H}_{2} \mathrm{O}\right)$ complex at $-30^{\circ} \mathrm{C}$.
The conformational mobility of the ethylene bridges leads to an exchange between the enantiomers, a mechanism which is similar to that observed in the corresponding $\operatorname{Ln}(D T P A)$ complexes.5,16 The barrier of these exchanges is determined by the eclipsing in the ethylene bridges at the transition state. As a result of relatively weak coordinating strength of the amide group with respect to carboxylate, a racemization process at the terminal $\mathrm{N}$-atoms could be observed, which involves decoordination and $\mathrm{N}$-inversion. In the DTPA complexes this process is too slow to be observed by line-shape analysis.

Acknowledgment. C.F.G.C.G. and A.M.U. acknowledge financial support from INIC (Portugal). Financial support from the Netherlands Organization for Scientific Research (NWO) is gratefully acknowledged by M.A.H. and J.A.P.

Supplementary Material Available: ${ }^{13} \mathrm{C}$ NMR spectra of $\mathrm{Ln}^{111}$ complexes of DTPA-PA $(\mathrm{Ln}=\mathrm{La}, \mathrm{Ce}, \mathrm{Pr}, \mathrm{Nd}, \mathrm{Sm}, \mathrm{Eu})$ (6 pages). Ordering information is given on any current masthead page. 